University of South Florida

DIGITAL COMMONS

Digital Commons @ University of

@ UNIVERSITY OF SOUTH FLORIDA

South Florida

QMaSC: A Handbook for Directors of

Quantitative and Mathematics Support Centers

USF Libraries

$1-1-2016$

\title{
19. Defining Staff Roles
}

Darry Andrews

The Ohio State University

Carolyn Johns

The Ohio State University

Follow this and additional works at: https://digitalcommons.usf.edu/qmasc_handbook

\section{Recommended Citation}

Darry Andrews, Carolyn Johns (2016), "Defining Staff Roles", http://dx.doi.org/10.5038/

9780977674435.ch19 in G. Coulombe, M. O'Neill, M. Schuckers (Eds.) A Handbook for Directors of Quantitative and Mathematical Support Centers, Neck Quill Press, http://scholarcommons.usf.edu/ qmasc_handbook.

This Starting a Center is brought to you for free and open access by the USF Libraries at Digital Commons @ University of South Florida. It has been accepted for inclusion in QMaSC: A Handbook for Directors of Quantitative and Mathematics Support Centers by an authorized administrator of Digital Commons @ University of South Florida. For more information, please contact digitalcommons@usf.edu. 


\title{
Defining Staff Roles
}

\author{
(c) Darry Andrews, Carolyn Johns,
} The Ohio State University

吅

\section{Introduction}

Staffing in a QMaSC assumes many structures depending on the size of the institution, budget constraints, number of students served, and the availability of qualified tutors. In the case of smaller institutions, the QMaSC may be part of a more encompassing academic learning center. Typically, at a minimum, the center or lab is staffed with a director or lab coordinator, and undergraduate or graduate student tutors. Tutors are also referred to as coaches, learning assistants, quantitative tutors, and more. The center may also employ a dministrative personnel or a pedagogy assistant. No matter what configuration of staff roles is determined to fit the needs of the institution best, a set of essential duties must be performed by the QMaSC staff.

\section{Philosophy of Center}

One of the first responsibilities of the staff is to determine the philosophy or mission statement of the QMaSC. The center philosophy should complement the institution's philosophy. In addition, the philosophy must be student-centered. Although some centers focus only on helping students answer homework questions, a better mission is to help students become self-motivated, independent learners, who eventually no longer need tutoring services. Tutoring sessions should be focused on the lasting effects of the session for the students.

While the staff may wish to create the center's philosophy, the tutors themselves, once hired, can be responsible for creating the philosophy through a training activity. This approach not only

Suggested Citation: Darry Andrews, Carolyn Johns (2016), "Defining Staff Roles", http://dx.doi.org/10. 5038/9780977674435.ch19 in G. Coulombe, M. O'Neill, M. Schuckers (Eds.) A Handbook for Directors of Quantitative and Mathematical Support Centers, Neck Quill Press, http://scholarcommons.usf.edu/qmasc_handbook

This material is based upon work supported, in part, by the National Science Foundation under Grant DUE1255945. Any opinions, findings, and conclusions or recommendations expressed in this material are those of the author(s) and do not necessarily reflect the views of the National Science Foundation 
allows tutors to reflect on their tutoring role but also to create ownership. [1]

\section{Tutoring Models}

The staff must also decide how to organize the center. What tutoring model will the center adopt? There are many options and combinations available. There are drop-in or appointmentbased models. There is group tutoring vs. one-on-one tutoring. Tutoring may occur with all subjects being tutored in one common room, or tutoring may occur with separate rooms or spaces for each course. Each combination has its advantages and disadvantages. The needs of the students, budget, and space available will determine the best model.

\section{One-on-One Appointment-Based Model:}

When to use: This model is best for students who need significant help in a course due to gaps in their knowledge, poor study skills, or low self-confidence. Example of Model: Students contact the center to make one-on-one appointments: either for a single appointment or a weekly appointment. Ideally, students can have a weekly appointment to see the same tutor.

Advantages: Students get individual, uninterrupted attention to focus on their needs. Students know they can get help at a specific time and don't feel as though they are wasting time waiting for a tutor. Weekly meetings are easy for students to remember; they are responsible for keeping their appointments; and it is relatively easy to monitor student progress and evaluations. Tutors can work on study skills, assign small tasks, and build rapport.

Disadvantages: A 1:1 ratio is less cost-effective than group tutoring; missed appointments waste tutors' time; it is harder to schedule last-minute appointments; and it makes no provision for students to have short questions answered.

Comments: Given a large budget, this is an ideal model to help students who struggle significantly.

\section{One-on-One Drop-in Model:}

When to use: This model is best for students who need significant help with a particular topic and for courses with lengthy homework problems. Example of model: When students arrive at the center, they are placed in a queue to meet with a tutor. As each tutor becomes available, he or she takes the next person in the queue to a private room for tutoring.

Advantages: Students get individual, uninterrupted attention to focus on their needs.

Disadvantages: Students may have to wait; tutors may not be able to meet with drop-ins. This model is less cost-effective than appointment-based one-on-one tutoring. Because students may see a different tutor each session, this model may prevent rapport building or hinder working toward long term goals. 
Comments: This model is somewhat impractical from a budget standpoint. Using appointments, either one-on-one or with groups, would be a better option.

\section{Group Appointment-based Model:}

When to use: This model is available when students need significant help in a course due to prior knowledge gaps, poor study skills, or low self-esteem, and the center's budget constraints do not allow for one-on-one tutoring. Example of Model: This model is similar to supplemental instruction. Students sign up for a weekly group meeting with a tutor. The tutor works with the group as a whole to handle the most common questions, encourages the group to answer their own questions, and provides help with study skills.

Advantages: This model is cost effective. It imposes no wait time for students; students can learn from each other; and having the same tutor allows rapport to build. Student progress can readily be tracked, and tutors can be evaluated.

Disadvantages: This model is not able to handle quick homework questions; students must have an appointment, and individual attention is limited.

Comments: Given a medium budget, this model may be the most beneficial way to balance both cost-effectiveness and regular appointments with the same tutor.

\section{Group Drop-In Model:}

When to use: This model is useful if the tutoring budget is low and when students mainly want a place to study with an expert around to answer quick questions. Example of model: Students work in a common room, tutors circulate and answer questions as needed.

Advantages: Tutors can help many students in a short amount of time, students can work in groups and on other problems while they wait for the tutor.

Disadvantages: Individual attention and student-tutor rapport are limited. It is difficult to work on long-term goals and difficult for students to work on study skills.

Comments: This model may be cost-effective in that tutors may be able to help many students quickly; however, it becomes less cost-effective when fewer students attend tutoring than anticipated in the schedule of tutors. Overall, this model is the least effective in helping students become independent learners. Tutors must be excellently trained and supervised for continuation of trained skills in order to ensure students are not simply getting answers to homework questions. In this model, all courses may be tutored in one common room, with distinct tables for each course, or courses may be grouped and placed into separate rooms.

A combination of these tutoring models may be used to meet the needs of all students and stay within budget. In addition, the center director should check with other campus tutoring services to see where gaps in tutoring need to be filled. 


\section{Center Roles and Responsibilities}

\section{Center Director}

In the case of the stand-alone center, the director or coordinator may be a faculty member or non-tenured staff member with a Master's or Ph.D. in a Mathematics/quantitative field. In the case of a larger academic learning center, the director or coordinator may have alternative degrees. In any case, the main duties of the director are to establish and execute the mission of the center, provide leadership, and manage all aspects of the center operations, including budgeting and staffing. Some centers may employ an assistant director to assume a subset of duties that are traditionally performed by the director. This may occur at larger research institutions where the sheer volume of students mandates this arrangement. Additionally, at some institutions, a director may have teaching obligations that take him/her away from the center. At smaller institutions where the tutoring occurs under the umbrella of an academic learning center, the director should have a liaison with departments or an assistant director to ensure the quality of the tutoring.

\section{Center Assistant Directors}

Some institutions may choose to hire an assistant director to fulfill some of the duties of the center. The assistant director may take on an administrative role of tracking appointments and tutors, as well as scheduling. The assistant director may be in charge of hiring, training, and evaluating tutors. The assistant director may hold a part-time position in charge of only one of the duties such as marketing, budgeting, record-keeping or processing of tutor timecards. How the director and assistant director divide tasks will depend on the size of the institution and each staff member's strengths and weaknesses. The assistant director should preferably have a master's degree in mathematics or another quantitative discipline, or in math education; however, the role could be filled by an individual with a bachelor's degree or a graduate student. The assistant director reports to the director of the center.

\section{Pedagogical Assistant}

The role of the pedagogical assistant may be filled by the director or assistant director or may be a stand-alone position. The pedagogical assistant may offer workshops and feedback to instructors on best math pedagogy practices. The pedagogical assistant may also be in charge of tutor training or creating/overseeing online materials for courses, and ideally should have a master's degree in math, in a quantitative subject, or in math education. The pedagogical assistant reports to the director of the center or to the appropriate administrator, if the position is a stand-alone one.

\section{Center Tutors}

Center tutors are responsible for the tutoring of students. Depending on the institution, tutors 
may be undergraduate or graduate students. In some instances, outside professionals serve as tutors.

Tutors may have some administrative responsibilities within the center. In the case of appointment-based tutoring, they may be responsible for keeping appointment records such as student progress, material covered, completing learning style inventories, and making appointments with their students. Tutors may be involved in marketing the center services to students through word of mouth and classroom visits. Tutors are responsible for reporting hours worked for payroll.

Center tutors may be senior tutors and junior tutors. Senior tutors possess extensive experience, while junior tutors are just beginning their career as a tutor. A third category is master tutor, which ranks above senior tutor and may be added in the exceptional tutor category. Tutors with excellent evaluations may be given higher pay, more hours, or preferred working hours. Master tutors may also assist in training and mentoring of junior tutors. All tutors may report to the director, assistant director, or center assistants.

As mentioned above, tutoring may take on many different forms. Regardless of the model used, center tutors must understand the mathematical content, have pedagogical knowledge of best tutoring practices, possess excellent customer service skills, and demonstrate use of study skills in their own studies. Tutoring should never be a homework service. Tutors must learn to put down their chalk or pencil and allow the students to take control. Tutors must learn to listen to students and use questions to find the misunderstandings as well as lead the students to the correct answer. A student who learns to find the correct answer on his/her own, rather than being given the answer, will learn how to problem-solve and eventually become an independent learner.

\section{Center Assistants}

If the math center assistant is a full-time employee, the assistant may perform clerical tasks and ensure correct record-keeping, as well as processing hired tutors' time sheets. However, the assistant's role may also be filled by student workers who perform such tasks as checking students in for appointments, ensuring tutoring rooms have supplies, and printing fliers. The math center assistants may also be responsible for tracking loan materials such as books and calculators if such services are offered by the center. The assistant reports to the director or assistant director. In some cases these assistants may be tutors with additional responsibilities.

\section{Other Staff Duties}

\section{Budgeting}

Budgeting for a QMaSC includes non-personnel costs for the physical tutoring space, cost of furniture, room decorations (such as posters and bulletin boards), office equipment, computers, software, and paper supplies. Personnel costs to be accounted for include the pay of the director, 
assistant director, tutors, administrative staff, and other personnel. Centers working with limited budgets can hire students with Federal Work Study Financial Aid, employ faculty on a volunteer basis, employ graduate students as part of their graduate student duties, or seek student volunteers. Another option would be to create tutoring as a course component of an education course. However, certain cost-cutting measures may leave a center with fewer high-quality applicants for tutor positions. A center may employ some combination of these types of employees to balance quality tutoring with budget constraints. When budgeting for hourly paid tutors, it is important to factor in time paid for training as well as extra staffing needed during exam periods.

\section{Scheduling}

The administrator must determine not only the hours the center will be open, but also how the center should be staffed. Budgeting, as well as the needs of the students, will greatly effect both of these facets of scheduling. Additionally, the model of tutoring being used will effect scheduling.

For appointment-based tutoring, the only constraints on hours of operations are the hours the tutors are available. Additionally, a supervisor should be available to assist during sessions. However, weekend and evening tutoring sessions might take place in a library, allowing a library staff member to serve as a supervisor during those times. TutorTrac software [2] is a great tool for managing appointment-based scheduling.

For drop-in tutoring, the hours will depend on the budget of the center and tutor availability. On a small budget, it is advisable to offer tutoring in the evening when it will be accessible to the majority of students. For residential campuses, evenings are a particularly advantageous time to offer tutoring. For non-residential campuses, evenings may not be advantageous, as many students will have left campus. In addition, residential campuses may offer tutoring on weekends, particularly Sundays, whereas non-residential campuses may not offer weekend tutoring. In any case, a center should make sure the hours meet the needs of the students. On some campuses, it may be feasible to poll students for the best times. If the center can only offer limited hours, the center should refrain from offer tutoring the same hours each night. On non-residential campuses and when budgeting allows, it is beneficial to offer daytime tutoring. This gives students a space to study while waiting for their next course and allows students to attend tutoring right before or after a class. Furthermore, student athletes and those involved in extracurricular activities may find it difficult to attend tutoring during the evening. Daytime tutoring hours greatly help these students.

Scheduling of tutors will vary depending on the tutoring model being used. With appointmentbased tutoring, tutors will be assigned to students, and the scheduling will be determined by the tutor and students. For drop-in tutoring, care should be given to staff more tutors during the busiest times of day. Ideally, the center will have a usage tracking system such as TutorTrac. For smaller colleges offering only a few sections of a course, one would expect the tutor room to have very few students while the course is taking place. Similarly, at large universities, many sections 
may be offered at the same time, rendering those times less popular. Additionally, extra staff will be needed on homework due dates and prior to exams. It is important to coordinate with instructors to determine when due dates and exams are.

Once the numbers of tutors needed during each hour of the day are determined, tutor availability needs to be collected. This can be collected through a survey tool such as Surveymonkey or Doodle. The staff will then place tutors according to center needs and tutor availability. For scheduling, one may choose software such as Microsoft Excel [3] or purchase an online scheduling software such as Shiftboard [4]. The center may find it beneficial to have a tutor schedule which repeats weekly while allowing for additional shifts added during exam weeks. However, for centers with tight budgets, it is more economical to use past semester student usage data, trends in the current semester's usage data, and course schedules to have a schedule which varies weekly. Additionally, for centers working with multiple rooms, it is important for the director to visit the rooms periodically as tutors may be asked to change rooms to help out in a particularly busy room.

\section{Marketing the Center}

Marketing, or publicizing the center, is one of the most important duties for a director and for the staff members of a QMaSC.

The necessity of marketing the center cannot be overstated. Often students and instructors are unaware of the existence of a center unless its services are properly advertised. Like any business, a center needs customers in order to prosper.

There are many ways a center can market itself. Starting at the local level, the center should place an abundance of signs around the center's location, instructors' offices, and classrooms announcing the center's presence and hours. Additionally, emails can be sent to students enrolled in supported courses as well as the instructors for those courses. A representative from the center needs to inform the instructors of the services before syllabi are made, and request that center information be printed on the syllabus or posted on the course website. Additionally, center staff or tutors, depending on the number of courses, should visit each course individually to introduce themselves and announce the center's services. They may take along fliers to hand out. Furthermore, the center can create a website and/or Facebook page with information regarding services. Before the start of the autumn term, some centers' staff meet with targeted student support groups, staff (particularly advisors), and faculty to inform them of the various services offered.

Marketing of the center does not stop after the beginning of the term. Emails, announcements, and website/Facebook updates must continue throughout the semester. These outreach efforts should increase student awareness of services offered by the center.

\section{Hiring Tutors}

There are many different ways to hire tutors. Depending on the program, the hiring of tutors 
may be subject to a variety of considerations and constraints. In some cases, hiring may be part of a lecturer's or graduate assistant's duties, so that tutors are not hired directly by the center. In others, budget constraints may limit the center director to hiring Federal Work Study students. Budgets may allow for students to be selected at will. In some programs, tutors may be handpicked after completing selected coursework, or tutors may be selected after they have completed a tutoring course.

The staff must seek to hire exceptional students who have demonstrated excellence in mathematics and other quantitative courses, or students who are referred by their math instructors, and who have interpersonal skills,. Such tutors typically major in mathematics, statistics, actuarial science, and engineering. However, students from all majors should be considered.

The first step in hiring is to have applicants fill out an application that includes past course grades, references, and their responses to questions such as why they wish to become QMaSC tutors. Some centers may have specific criteria for undergraduate tutors such as achieving A's and B's in upper division mathematics courses and a minimum GPA of at least a 3.0. In contrast, other centers prefer students with only A's or B+'s in the course they are tutoring or the next course in the sequence. (See the chapter on "Staffing and Hiring" by Christine Tinsley.)

Once the pool of applicants has been screened by performance in previous course work, the QMaSC staff conducts interviews to determine if undergraduate students possess the interpersonal and communication skills necessary to work with many different types of students. At the time of the interview, a diagnostic quiz may be administered. This quiz consists of problems students typically struggle with and is used to evaluate the applicant's ability to assist other students in these topic areas. At some colleges, administrators use the information from this test to place tutors into categories of expertise (e.g., introductory calculus, advanced statistics, etc.) and tutors work with students only in specific categories.

The final portion of the interview process consists of a tutoring scenario. Prior to the interview, applicants are given a few short readings on tutoring pedagogy to read to help them prepare for the interview. During the interview, the applicant is asked to help a confused student with a homework problem. During this portion of the interview, the staff observes to see how tutors interact with students, their capabilities in explaining concepts, and their pedagogical knowledge of the tutoring process. These scenarios also help the director determine the training needs of the tutors.

In some cases, the staff may choose not to use the application process model for hiring. The director may offer an open tutoring training course for all interested applicants. The applicant goes through several sessions of training and at the end, is asked to perform tutoring scenarios. This model may be preferred, as only applicants who are serious about tutoring will attend the training. In addition, tutors are now trained when they begin, and it allows the staff to see tutors' potential after training, rather than judging tutors prior to being trained. 


\section{Training Tutors}

Tutor training can take many different forms. Directors may choose to train tutors as part of the hiring process, create a tutor training course, administer initial training, or administer on-going training. In addition, these trainings may take place in-person, online, or consist of readings and discussion posts. In any form, training should be interactive and follow educational best practices. Tutors will need to be trained on the essence of tutoring: how is it different from teaching? In addition, tutors will need to learn center policies and procedures, as well as the philosophy of the center. Tutors learn how to manage sessions and provide excellent customer service. Tutors need training in greeting students, defining goals with students, and closings. Tutors learn how to help students develop problem-solving skills, rather than providing answers directly to students, by asking probing questions and listening to the students as they talk through their problem-solving process. Tutors learn how to accurately identify the part of a concept that confuses students. For returning tutors, training on more advanced topics such as difficult students, learning styles, and additional goal development may be offered. In addition, center directors may choose to have excellent returning tutors mentor new tutors. This can be done through shadowing opportunities.

\section{Evaluating Tutors}

Tutors should be evaluated at least once, if not twice, a year. For an evaluation, the staff should sit in on a tutoring session and observe the tutor at work. Other sources, such as student evaluations of their tutoring experiences should also be taken into consideration. Ideally, the evaluation period should occur after a majority of the tutor training has occurred.

There are many reasons for evaluating tutors. Evaluations determine the effectiveness of each tutor. This may determine their future employment or hours at the center. Areas which need addressed by further training for all tutors can also be brought to light during evaluations. Most important, the staff can give tutors feedback on how to improve their sessions and become better tutors. Through these evaluations, excellent tutors may be identified who can serve as mentors for new tutors.

\section{Tracking Tutor Attendance}

Daily tutor attendance must be tracked to ensure tutors are present and on time for their shifts. A system of tutor notification and ongoing tracking for missed or late arriving shifts should be in place. In addition, a tardy and absent policy should be in place for tutors. Late or absent tutors undermine the mission of the center.

\section{Tutor Payroll}

Staff must also ensure tutor payroll is tracked and human resource needs are met. It is important to track payroll throughout the term to ensure the center stays within its budget. In addition, all 
proper work documentation and tax forms need to be filed. Usually this paperwork is performed by staff in the institution's human resources department.

\section{On-going Needs Assessment}

The staff must be aware of the on-going needs of the center. This includes daily monitoring of rooms to ensure the quality of tutoring and adherence to center policies. In addition, the staff needs to be aware of the attendance in the tutoring rooms to determine when additional tutors or fewer tutors are needed. Low attendance may indicate that further marketing is needed to make the students aware of the center or may indicate that the center's hours are inconvenient to students. Software such as TutorTrac is helpful in monitoring center usage. Usage data can also be used to justify the center's existence. In cases where students are receiving appointment-based tutoring, grades may be tracked using GradesFirst [5] software. Evidence of improvement in grades or success in courses can be used to build support for the center.

Staff should also monitor students' appraisal of the center. Dissatisfied students spread the word, and the center will soon lose its clientele. Staff must work to ensure the center has happy customers. Student feedback on center performance should be collected via periodic surveys or by using a suggestion box.

\section{Supporting Courses with Other Materials}

In addition to providing tutoring services, a QMaSC may choose to support courses with other aids. For example, a center may offer courses in study skills, provide exam review workshops, or provide additional resources for particularly hard topics in courses. A center may hold workshops that provide extra explanations and problems for students to do while an instructor or center staff member is present for questions. A center may furnish a set of lecture videos online for student use. In addition, the center may house a library of textbooks and calculators to be checked out. At some institutions this role may also be filled by the library. Center staff may work with course instructors to ensure best teaching practices are used. Center staff may also assist instructors through grading or printing services.

\section{Conclusion}

The center staff configuration is up to the discretion of the director and institution. The number and type of staff a center employs depends greatly on the size of institution, available budget, and level of demand for tutoring and other services. In any case, the essential duties of the center must be carried out by center staff. The division of labor will depend on the skill set of each staff 
member. Once hired, the director may choose to define the scope of the staff roles by defining their duties and may perform a search for additional staff with the duties of each role in mind. On the other hand, a director may be given an existing staff and must assess the duties each staff member and determine their level of competency based on their existing duties. The various configurations for reporting depend on the center's needs.

\section{Bibliography}

[1] K. S. Agee and R. Hodges, Handbook for Training Peer Tutors and Mentors. Cengage Learning, 2012 .

[2] Redrock Software Corporation, "Tutortrac." http://www.tutortrac.com/, 2013.

[3] Microsoft Corporation, "Microsoft Excel version 2013," 2013.

[4] Shiftboard Inc., "Shiftboard." http://www.shiftboard.com/, 2013.

[5] GradesFirst, "Gradesfirst advising management system." http://www.gradesfirst.com/, 2013. 